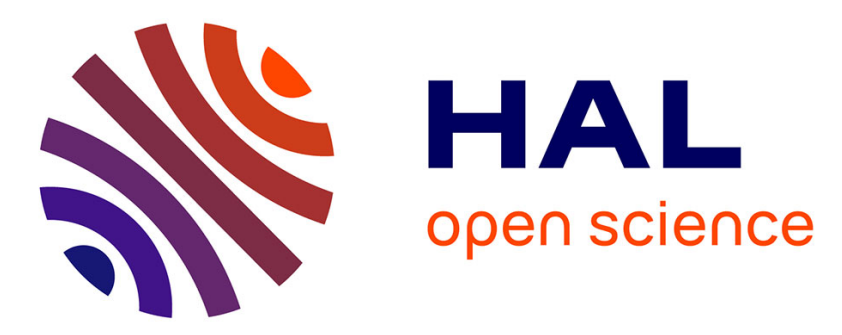

\title{
Physico-chemical environment of Al impurity atoms in amorphous silica
}

\author{
Ph Jonnard, J.-P Morreeuw, H Bercegol
}

\section{To cite this version:}

$\mathrm{Ph}$ Jonnard, J.-P Morreeuw, H Bercegol. Physico-chemical environment of Al impurity atoms in amorphous silica. European Physical Journal: Applied Physics, 2003, 21, pp.147-149. 10.1051/epjap:2002109 . hal-01346820

\section{HAL Id: hal-01346820 \\ https://hal.science/hal-01346820}

Submitted on 19 Jul 2016

HAL is a multi-disciplinary open access archive for the deposit and dissemination of scientific research documents, whether they are published or not. The documents may come from teaching and research institutions in France or abroad, or from public or private research centers.
L'archive ouverte pluridisciplinaire HAL, est destinée au dépôt et à la diffusion de documents scientifiques de niveau recherche, publiés ou non, émanant des établissements d'enseignement et de recherche français ou étrangers, des laboratoires publics ou privés. 


\title{
Physico-chemical environment of Al impurity atoms in amorphous silica
}

\author{
Ph. Jonnard ${ }^{1, a}$, J.-P. Morreeuw ${ }^{2}$, and H. Bercegol ${ }^{2}$ \\ 1 Laboratoire de Chimie Physique-Matière et Rayonnement, Université Pierre et Marie Curie, UMR-CNRS 7614, \\ 11 rue Pierre et Marie Curie, 75231 Paris Cedex 05, France \\ 2 CEA/CESTA, BP 2, 33114 Le Barp, France
}

Received: 5 July 2002 / Received in final form: 9 October 2002 / Accepted: 11 October 2002 Published online: 29 November 2002 - (C) EDP Sciences

\begin{abstract}
The physico-chemical environment around the aluminum impurity atoms in commercial Herasil silica is studied by electron-induced X-ray emission spectroscopy. Despite the low concentration of aluminum and the charging effect occurring upon electron irradiation, we have been able to characterize the environment of the $\mathrm{Al}$ atoms. We show that the $\mathrm{Al}$ atoms are in an octahedral environment, i.e. surrounded by 6 oxygen atoms. The presence of Al clusters, whose metallic character would make them candidates to be ultraviolet absorption centers, is ruled out.
\end{abstract}

PACS. 78.70.-g Interactions of particles and radiation with matter - 78.20.-e Optical properties of bulk materials and thin films - 71.55.Jv Disordered structures; amorphous and glassy solids

\section{Introduction}

The identification of absorption centers in silica $\left(\mathrm{SiO}_{2}\right)$ glass is of major importance. Indeed, high quality silica glasses are used for their optical properties in high power ultraviolet lasers. They are essential for lasers that are now under construction like MégaJoule [1] and NIF [2] facilities. Because of the high peak power density $\left(>5 \mathrm{GW} / \mathrm{cm}^{2}\right)$ and fluence $\left(>12 \mathrm{~J} / \mathrm{cm}^{2}\right)$ involved in the laser transport line of these experiments, even a low concentration of defects can produce damages in the optical systems. In this work, we focus on aluminum impurity in amorphous silica.

\section{Experiment}

\subsection{Sample}

The glass sample is a commercial Herasil silica polished to an optical finish, with a bulk Al concentration of $10-50 \mathrm{ppm}$ in weight. A superficial layer of a few $\mu \mathrm{m}$ was removed by etching, i.e. by dipping one face of the sample in HF $40 \%$ for 5 min. Thus, it is expected that any contamination left by the alumina powder used in the polishing process would be removed by this etching. Herasil silica is one of several possible materials in Mégajoule optics. It

\footnotetext{
a e-mail: jonnard@ccr.jussieu.fr
}

has been chosen in this study because of its relatively high impurity concentration.

\subsection{EXES}

In electron-induced X-ray emission spectrometry (EXES) [3], the sample is irradiated by an electron beam, causing the ionization in the core shells of the atoms. Photons are emitted during the radiative recombination of the ionized atoms. The transitions can take place from another core level or from the valence band, leading to the emission of characteristic $\mathrm{X}$-rays giving rise to spectral lines or bands, respectively. Because of the local character of the core hole involved in the transition and of the dipole selection rules, the observed spectral densities depend on the element and on the symmetry of states.

Because of the low aluminum concentration, we selected for the analysis the most intense emission of the $\mathrm{Al}$ spectrum. It is the $\mathrm{Al} K \alpha_{1,2}$ doublet (transitions $2 p_{3 / 2,1 / 2} \rightarrow 1 s$, around $\left.1487 \mathrm{eV}\right)$. The position of the maximum of this emission is sensitive to the physicochemical environment around the $\mathrm{Al}$ atoms [4]. The X-ray spectra are registered with a high resolution wavelength dispersive spectrometer [5], using a quartz (10 $\overline{1} 0)$ crystal at the first reflection order. In our experimental conditions, the relative spectral resolution $E / \Delta E$ is about 5000 . 


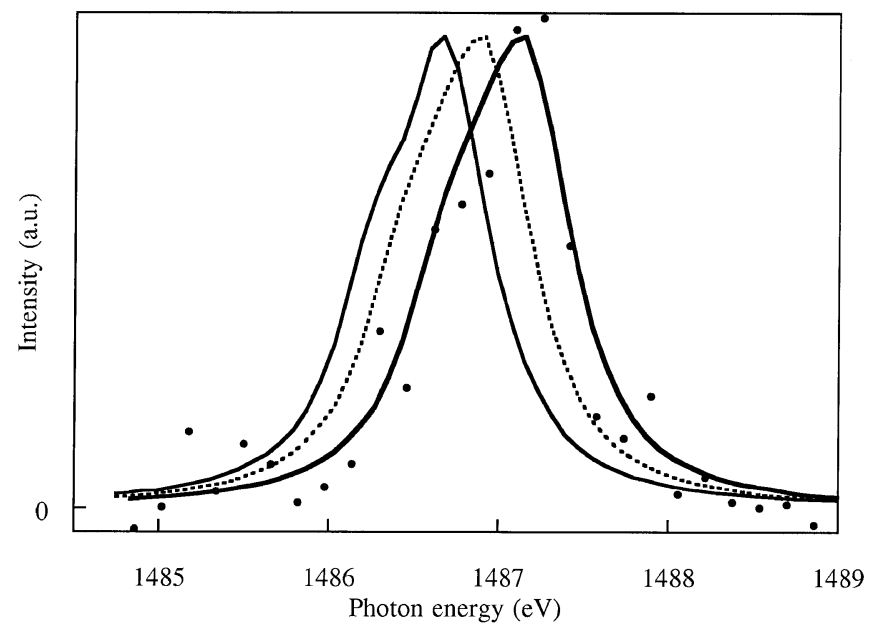

Fig. 1. Al $K \alpha_{1,2}$ emission of $\mathrm{Al}$ in silica glass sample (dots). Comparison with reference spectra: Al metal (thin solid line), $\mathrm{Al}$ in octahedral environment (thick solid line) and $\mathrm{Al}$ in tetrahedral environment (dashed line).

The conditions of the electron bombardment were: energy of $8 \mathrm{keV}$ and current density of $1 \mathrm{~mA} / \mathrm{cm}^{2}$. Note that this electron current density is much lower than that used in classical electron probe microanalysis (typically $1 \mathrm{nA}$ in a $100 \times 100 \mathrm{~nm}^{2}$ spot, i.e. $\left.10^{4} \mathrm{~mA} / \mathrm{cm}^{2}\right)$. The electron beam forms a $1 \mathrm{~cm}$ diameter spot on the sample. The spectra were accumulated during about $1 \mathrm{~h}$. The total duration of the experiment was 2 days. Because of the charging effect occurring with this insulating sample, some spectra were disturbed by large intensity variations. These spectra were rejected and the presented spectrum results from the accumulation of 13 spectra obtained under stable conditions. Note that the energy of the emitted photons is not sensitive to the charging effect.

The analysed thickness is estimated to be $500 \mathrm{~nm}$, by using a semi-empirical simulation model dedicated to the simulation of the generation of the characteristic X-rays under electron irradiation $[6,7]$. Due to the charging effect, one expects this value to be an upper limit, because the trapped electrons inside the sample produce an electric field which slows down the electron beam [8]. This prevents the use of the intensity measurement, as is conventionally done in electron probe microanalysis, to quantify the $\mathrm{Al}$ concentration in the silica.

\section{Results and discussion}

We present in Figure 1 the $\mathrm{Al} K \alpha_{1,2}$ emission from the aluminum impurities in the Herasil sample. The background emission has been subtracted. The full width of the peak at half maximum is $0.93 \pm 0.06 \mathrm{eV}$ and the position of its maximum energy is at $1487.16 \pm 0.10 \mathrm{eV}$. This emission is compared to reference spectra of aluminum metal and aluminum in two different oxide environments. The spectra are normalized with respect to their maximum.

For the metal, the peak's width is $0.86 \pm 0.03 \mathrm{eV}$ and its maximum energy is $1486.71 \pm 0.03 \mathrm{eV}$. Two oxides have been studied: the $\alpha$-alumina where all the aluminum atoms are in octahedral environment (surrounded by an octahedron of oxygen atoms) and a poorly crystallized $\gamma$-alumina where the aluminum atoms are both in octahedral and in tetrahedral environment (surrounded by a tetrahedron of oxygen atoms) [9]. The width and maximum energy for the $\alpha$-alumina sample are respectively $0.92 \pm 0.04 \mathrm{eV}$ and $1487.15 \pm 0.03 \mathrm{eV}$. Concerning the $\gamma$-alumina, the $\mathrm{Al} K \alpha$ spectrum can be decomposed into the sum of two doublets, one corresponding to that of the $\alpha$-alumina ( $\mathrm{Al}$ in octahedral environments) and another corresponding to the $\mathrm{Al}$ atoms in tetrahedral environment. For this last environment, the width is $0.92 \pm 0.05 \mathrm{eV}$ and the maximum is located at $1486.91 \pm 0.04 \mathrm{eV}$. These positions of the maximum for the octahedral and tetrahedral sites are in agreement with the previous determination as a function of the coordination of the $\mathrm{Al}$ atoms in a series of compounds [4].

From the energy position of the $\mathrm{Al} K \alpha_{1,2}$ line characteristic of the impurities in the glass, the presence of metallic Al in Herasil can be ruled out. From the energy position and the width of the observed spectral density, it can be concluded that more than $90 \%$ of the $\mathrm{Al}$ atoms are in octahedral environment and the rest could be in tetrahedral environment. Indeed, because of the counting statistics, a weighted sum of the doublets corresponding to the octahedral and tetrahedral environments would lead to a reasonable fit of the Herasil spectrum, provided that the tetrahedral contribution is less than $10 \%$. In the case of a tetrahedral environment, the $\mathrm{Al}$ atoms would be in substitution of the $\mathrm{Si}$ atoms. It seems more reasonable to think that the aluminum impurity atoms are located in insertion positions, inside the large voids of the silica glass structure. Indeed, the local structure (over a $1 \mathrm{~nm}$ length scale) of amorphous silica has similarities with that of the $\beta$-cristobalite [10]. In the voids surrounded by oxygen octahedrons of such a structure, the aluminum atoms would have an environment close to that they have inside the $\alpha$-alumina, in term of Al-O bond length and O-Al-O angle.

\section{Conclusion}

The physico-chemical environment of the Al impurity atoms in a Herasil glass has been studied by EXES. Within the analysed thickness, the presence of aluminum metallic clusters, which would be candidates for absorption in the ultraviolet can be ruled out. From the position of the Al $K \alpha_{1,2}$ maximum, it is deduced that the major part of the $\mathrm{Al}$ atoms are in octahedral environment, i.e. each surrounded by 6 oxygen atoms.

The authors wish to thank Pr. C. Bonnelle for helpful discussions and J. Néauport (CEA/CESTA/DLP/SCPL/LTO) for providing information about the sample. 


\section{References}

1. M.L. André, Proc. SPIE 3578, 766 (1998)

2. Solid State Lasers for Application to Inertial Confinement Fusion (ICF), edited by W.F. Krupke, Proc. SPIE 2633 (1995)

3. C. Bonnelle, Annual Report C, Royal Society of Chemistry, London, 1987, p. 201

4. D.E. Day, Nature 4907, 649 (1963)

5. C. Bonnelle, F. Vergand, P. Jonnard, J.-M. André, P.-F. Staub, P. Avila, P. Chargelègue, M.-F. Fontaine,
D. Laporte, P. Paquier, A. Ringuenet, B. Rodriguez, Rev. Sci. Instrum. 65, 3466 (1994)

6. P.-F. Staub, X-ray Spectrom. 27, 43 (1998)

7. P.-F. Staub, P. Jonnard, F. Vergand, J. Thirion, C. Bonnelle, X-ray Spectrom. 27, 58 (1998)

8. C. Hombourger, P. Jonnard, E.O. Filatova, V. Lukyanov, Appl. Phys. Lett. 81, 2740 (2002)

9. M. Kefi, P. Jonnard, F. Vergand, C. Bonnelle, E. Gillet, J. Phys.-Cond. Matter 5, 8629 (1993)

10. D.A. Keen, M.T. Dove, J. Phys.-Cond. Matter 11, 9263 (1999) 